\title{
Anthelmintic tolerance in free-living and facultative parasitic isolates of Halicephalobus (Panagrolaimidae)
}

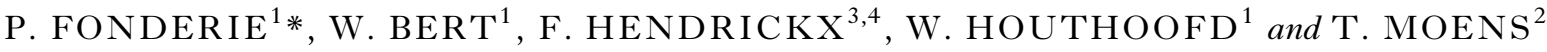 \\ ${ }^{1}$ Nematology Unit, Department of Biology, Ghent University, K.L. Ledeganckstraat 35, 9000 Ghent, Belgium \\ ${ }^{2}$ Marine Biology Section, Department of Biology, Ghent University, Krijgslaan 281 S8, 9000 Ghent, Belgium \\ ${ }^{3}$ Terrestrial Ecology Unit, Department of Biology, Ghent University, K.L. Ledeganckstraat 35, 9000 Ghent, Belgium \\ ${ }^{4}$ Royal Belgian Institute of Natural Sciences, rue Vautiers 29, 1000 Brussels, Belgium
}

(Received 22 March 2011; revised 21 November 2011, 23 February and 2 March 2012)

\begin{abstract}
SUMMARY
Studies on anthelmintic resistance in equine parasites do not include facultative parasites. Halicephalobus gingivalis is a freeliving bacterivorous nematode and a known facultative parasite of horses with a strong indication of some form of tolerance to common anthelmintic drugs. This research presents the results of an in vitro study on the anthelmintic tolerance of several isolates of Halicephalobus to thiabendazole and ivermectin using an adaptation of the Micro-Agar Larval Development Test hereby focusing on egg hatching and larval development. Panagrellus redivivus and Panagrolaimus superbus were included as a positive control. The results generally show that the anthelmintic tolerance of Halicephalobus to both thiabendazole and ivermectin was considerably higher than that of the closely related Panagrolaimidae and, compared to other studies, than that of obligatory equine parasites. Our results further reveal a remarkable trend of increasing tolerance from fully freeliving isolates towards horse-associated isolates. In vitro anthelmintic testing with free-living and facultative parasitic nematodes offers the advantage of observing drug effect on the complete life cycle as opposed to obligatory parasites that can only be followed until the third larval stage. We therefore propose Halicephalobus gingivalis as an experimental tool to deepen our understanding of the biology of anthelmintic tolerance.
\end{abstract}

Key words: facultative parasitism, ivermectin, MALDT method, thiabendazole, model organism.

\section{INTRODUCTION}

To date, studies on anthelmintic resistance or tolerance in equine parasites only include obligatory parasites, not facultative parasites. Halicephalobus gingivalis (Stefánsky, 1954, Andrássy, 1984) also referred to as $H$. deletrix or as Micronema deletrix (Anderson et al. 1998), is a small $(235-460 \mu \mathrm{m})$ freeliving bacterivorous nematode (Panagrolaimidae) and a known facultative parasite of horses (Blunden et al. 1987; Nadler et al. 2003) and zebra (Isaza et al. 2000). In addition, 4 cases of human infection, all with a fatal outcome, have been described (Ondrejka et al. 2010). H. gingivalis has all the characteristics of a free-living nematode, only at the ultrastructural level can some potential adaptations to facultative parasitism be observed (Fonderie et al. 2009). Infection probably occurs through open wounds and oral or nasal cavities (Pearce et al. 2001). Subsequently, nematodes most likely invade the bloodstream and lymphatic system and thus reach different organs (e.g. kidneys, liver and brain) where the number of nematodes increases rapidly through parthenogenetic reproduction (Akagami et al. 2007).

* Corresponding author: Nematology Unit, Department of Biology, Ghent University; K.L. Ledeganckstraat 35, 9000 Ghent, Belgium. Tel: +3292645225 . Fax: +32 92645344. E-mail: Pamela.Fonderie@UGent.be
The clinical symptoms vary depending on which organs are infected (Blunden et al. 1987; Spalding et al. 1990; Rames et al. 1995; Johnson et al. 2001; Müller et al. 2008). A few cases have been described in which the infection was recognized in time and the horse was successfully treated (Dunn et al. 1993; Pearce et al. 2001; Müller et al. 2008). Still, most infections were only recognized post-mortem after a thorough autopsy. Most importantly, the clinical histories of all reported equine infections show that the horses had been regularly treated with common anthelmintics (e.g. Boswinkel et al. 2006, Ferguson et al. 2008). This strongly indicates that $H$. gingivalis either has a high tolerance or some form of resistance to these anthelmintic drugs.

The current paper presents the first research on anthelmintic tolerance of the facultative parasitic nematode Halicephalobus gingivalis. Several isolates were tested for tolerance to common anthelmintic drugs through in vitro experiments focusing on egg hatching and larval development. Both free-living and parasitic isolates were included to examine whether tolerance is restricted to parasitic isolates or whether it also holds true for free-living isolates. The results on the $H$. gingivalis isolates were compared with those on the closely related free-living nematode species Panagrellus redivivus and Panagrolaimus superbus, allowing us to discriminate species- or 
strain-specific tolerance from any more general tolerance in the free-living Panagrolaimidae.

\section{MATERIALS AND METHODS}

\section{Maintenance of cultures}

We selected 4 isolates for our experiments. They were all light-microscopically identified as the morphospecies Halicephalobus gingivalis using different identification keys (Geraert et al. 1988; Shokoohi et al. 2007). No males were observed confirming that this species is parthenogenetic (Stefansky, 1954; Andrássy, 1984; Akagami et al. 2007; Fonderie et al. 2009). The JB128 isolate was obtained from a vegetable compost heap in Riverside (California, USA). The WB0708 isolate was obtained from a large-scale compost heap (Steel et al. 2010) at the Institute for Agricultural and Fisheries Research in Merelbeke (Belgium). The WB0801 isolate was obtained from fresh horse droppings from an individual stall on a stable in the province of WestFlanders (Belgium). The SAN100 isolate is a clinical isolate originating from an infection in a horse (Guelph, Ontario, Canada) described by Anderson et al. (1998). SAN100 has been maintained in culture on plain bacteriological agar with a bacterial food source since its isolation. Hence, we used 2 compost isolates from horse-independent habitats and 2 isolates from horse-associated habitats including 1 parasitic isolate and 1 isolate found in the near vicinity of horses. Two closely related free-living species, Panagrellus redivivus PS1163 and Panagrolaimus superbus DF5050, were included in the experiments to discriminate species- or strain-specific tolerance from a possible more general tolerance in the otherwise free-living Panagrolaimidae.

Stock cultures of all species were maintained on $1 \%$ bacteriological agar (Oxoid, Basingstoke, UK) plates containing cholesterol $\left(1 \mathrm{mg} \mathrm{ml}^{-1}\right)$ and Escherichia coli OP50 as a food source. The stock cultures were incubated at $20^{\circ} \mathrm{C}$ and generally handled as described by Brenner (1974). To provide enough eggs to start the experiments, the Halicephalobus isolates were subcultured and incubated at $37^{\circ} \mathrm{C}$ for 3 to 4 days. At this temperature the cultures grow fast and numerous eggs can be generated over a short period of time. The $P$. redivivus and $P$. superbus isolates were subcultured 2 weeks beforehand and incubated at $20^{\circ} \mathrm{C}$ to yield a sufficient amount of eggs.

\section{Anthelmintics}

The anthelmintics used in the experiments were thiabendazole (TBZ; Sigma-Aldrich, Bornem, Belgium) and ivermectin (IVM) that represent members of 2 important anthelmintic groups, the benzimidazoles and the avermectin/mylbecins, respectively. They were selected because of the use of products of these groups on the location where the WB0801 isolate was found. TBZ is the most soluble member of the benzimidazole group that facilitates in vitro experiments. The IVM used in the experiments are dilutions of Ivomec ${ }^{\circledR}$ Injection (Merial, Brussels, Belgium), a commercially used form of the drug.

\section{Experimental setup}

The technique used was a modification of the microagar larval development test (MALDT) (Coles et al. 2006). The MALD'T method was originally designed as a larval development test (LDT) on a solid instead of in a liquid medium. MALDT was chosen over LDT because of the ease of culturing Halicephalobus on solid medium and because this very small nematode is easier to discern on solid than in liquid medium. The main objective of any larval development test is to follow the development of nematode eggs onto third-stage larvae, which generally is the infective stage in obligatory animal parasites. Here we mainly focused on quantitative hatching data and development to the adult stage.

The experiments were performed on 24-well plates (Greiner Bio-One, Frickenhausen, Germany). The anthelmintics were dissolved in 100\% dimethylsulfoxide (DMSO; Carl Roth GmbH, Karlsruhe, Germany). Five stock solutions of TBZ (100, 1000, 2000, 5000, $10000 \mu \mathrm{g} \mathrm{ml}^{-1}$ ) and 5 stock solutions of IVM $\left(1,10,50,100,200 \mu \mathrm{g} \mathrm{ml}^{-1}\right)$ were prepared. Stock solutions were diluted $100 \mathrm{x}$ by adding $49 \cdot 5 \mathrm{ml}$ of $1 \%$ bacteriological agar at approximately $45{ }^{\circ} \mathrm{C}$ to $0.5 \mathrm{ml}$ of drug solution in a $50 \mathrm{ml}$ Falcon flask. The final solution was carefully homogenized before adding $3 \mathrm{ml}$ to each well. The control consisted of $1 \%$ bacteriological agar with a final concentration of $1 \%$ DMSO. We chose to keep the concentration of DMSO in the final solutions at $1 \%$ to exclude any influence on the mortality rate as reported for Caenorhabditis elegans by Ura et al. (2002) for DMSO concentrations in excess of $5 \%$. Final drug concentrations in the wells were $1,10,20,50$ and $100 \mu \mathrm{g} \mathrm{ml}^{-1}$ for TBZ and $0 \cdot 01,0 \cdot 1,0 \cdot 5,1 \cdot 5$, and $2 \mu \mathrm{g}$ $\mathrm{ml}^{-1}$ for IVM. Initially, the Halicephalobus isolates were tested against a range of drug concentrations based on Várady et al. (2009). Because only small to no effects were noticed, higher concentrations were chosen in the present experiments.

The tests were performed in 3 replicates for each anthelmintic concentration with the zero concentration as a negative control. Approximately 50 nematode eggs were transferred into each well. The exact number of eggs was counted for each well. The plates were subsequently incubated at an optimal temperature for development, i.e. $30{ }^{\circ} \mathrm{C}$ for the Halicephalobus isolates and $20^{\circ} \mathrm{C}$ for $P$. redivivus and $P$. superbus. Hatching was quantified at the time eggs normally develop into the adult stage, which is 
after $48 \mathrm{~h}$ incubation at $30^{\circ} \mathrm{C}$ for the Halicephalobus isolates and after 7 days incubation at $20^{\circ} \mathrm{C}$ for $P$. redivivus and $P$. superbus. In order to assess the reproducibility of our bioassay, we repeated the entire experiment 15 months after the first trial.

The hatching proportion (HP) is calculated for each well as follows: the number of hatched eggs and surviving larvae or adults is divided by the number of eggs originally transferred onto the agar. This proportion is determined at each concentration.

Moreover, in contrast to TBZ which prevents both embryonation and hatching of nematode eggs (Taylor et al. 2002), IVM mainly has an effect on the larval stage and only prevents hatching at very high concentrations (Patel, 1997). Therefore, an experiment was performed to verify whether larval stages surviving high IVM concentrations but initially not developing into the adult stage, can overcome the effect of drug treatment and resume development. To this end, 3 replicas of 40 eggs of each Halicephalobus isolate were transferred onto $1 \%$ bacteriological agar containing $1.5 \mu \mathrm{g} \mathrm{ml}^{-1} \mathrm{IVM}$ and were incubated at $30^{\circ} \mathrm{C}$. After $76 \mathrm{~h}, 20$ surviving larvae of each replicate were transferred onto plain $1 \%$ bacteriological agar and observed for several days. Their recovery rate is defined as the number of transferred larvae that develop into the adult stage divided by the number of initially transferred larvae $\times 100$.

\section{Effect of pre-exposure on anthelmintic tolerance}

Anthelmintic tolerance can be caused or increased by contact of the nematodes with the anti-parasitic drug in question. In order to verify the short-term effect of a prior anthelmintic treatment on the anthelmintic tolerance of Halicephalobus cf. gingivalis, all 4 isolates (JB128, WB0708, SAN100 and WB0801) were cultured for approximately $12 \pm 2$ generations at $30{ }^{\circ} \mathrm{C}$ on $1 \%$ bacteriological agar containing a low dose of anthelmintics, i.e. $10 \mu \mathrm{g} \mathrm{ml}^{-1} \mathrm{TBZ}$ or $0 \cdot 01$ $\mu \mathrm{g} \mathrm{ml}^{-1}$ IVM. After this period, the modification of the MALDT method was performed as described above, leaving out the lowest TBZ concentration of $1 \mu \mathrm{g} \mathrm{ml}^{-1}$.

\section{Statistical analysis}

To test for differences in the response of the isolates towards each anthelmintic across the two trials, the data were modelled by means of a generalized linear mixed model (PROC GLIMMIX in SAS ${ }^{\circledR}$ v.9.3, SAS Institute Inc., Cary, NC, USA). As we were merely interested in the effect of 'isolate' and 'concentration' and their interaction, these factors were treated as fixed effects in the model. Yet, as the whole experiment was replicated in 2 trials, the fixed effects were assessed across both trials by including the factor 'trial' as random effect in the model. As the response variable includes the number of hatched or survived individuals on the total number of individuals, a binomial error distribution was assumed and a logit link was incorporated to relate the predictive part of the model to the mean response. Standard error and degrees-of-freedom were estimated according to the method described by Kenward and Roger (1997). Significance of the fixed effects and their interactions were tested by means of Type III tests. Differences in tolerance between the isolates were post-hoc tested by comparing the expected hatching success and survival probability at different concentrations (least square means), using a TukeyKramer-adjustment to correct for multiple testing.

Given that generalized linear mixed models are large sample tests (Agresti, 2002), we did not rely on this procedure to compare the effect of the anthelmintics between the Halicephalobus isolates and $P$. redivivus and $P$. superbus as their hatching proportion approached zero at higher concentrations. Therefore, a Fisher exact test procedure was used for these comparisons as implemented in StatXact ${ }^{\circledR}$ v.5.0 (Cytel Inc., Cambridge, MA, USA).

The effect of pre-exposure to anthelmintics was analysed using Statistica 7 (StatSoft Europe GmbH, Hamburg, Germany) for each Halicephalobus isolate separately using two-way analysis of variance (ANOVA) with the factors anthelmintic concentration and pre-exposure, followed by a post-hoc Tukey HSD test. The assumptions for ANOVA (normality and homogeneity of variances) were tested using a Kolmogorov-Smirnov test and a Bartlett test, respectively.

\section{RESULTS}

\section{Thiabendazole (TBZ)}

Figure 1 shows the mean hatching proportions (HPs) of the Halicephalobus isolates and of $P$. redivivus and $P$. superbus for both trials at different TBZ concentrations, with $0 \mu \mathrm{g} \mathrm{ml}^{-1}$ being the negative control. The mean HPs of the negative controls were comparable for the parasite isolate, the droppings isolate, $P$. redivivus and $P$. superbus, with an average ranging from 0.96 to 0.99 . However, the HPs of the negative controls of the compost isolates, with an average ranging from 0.91 to 0.93 , were significantly (Tukey post-hoc, $P<0.0001$ ) lower than those of the parasite isolate and the droppings isolate.

The response of $P$. redivivus and $P$. superbus to TBZ concentration was similar in both trials; they had an initially high $\mathrm{HP}$ with an average ranging from 0.85 to 0.94 at $1 \mu \mathrm{g} \mathrm{ml}^{-1}$ followed by a steep decrease towards zero hatching at $10 \mu \mathrm{g} \mathrm{ml}^{-1}$ and higher TBZ concentrations. From $10 \mu \mathrm{g} \mathrm{ml}^{-1}$ onwards, the HPs of both $P$. redivivus and $P$. superbus were significantly 
Table 1. Type III statistics of fixed effects generated by means of a generalized linear mixed model on the average hatching proportions (HPs)

\begin{tabular}{lccccc}
\hline \hline & \multicolumn{2}{c}{ TBZ } & & \multicolumn{2}{c}{ IVM } \\
\cline { 2 - 3 } \cline { 5 - 5 } Effect & $F$ value & $P$ & & $F$ value & $P$ \\
\hline isolate & 85 & $<0 \cdot 0001$ & 64 & $<0 \cdot 0001$ \\
concentration & 604 & $<0 \cdot 0001$ & & 275 & $<0 \cdot 0001$ \\
concentration*isolate & $5 \cdot 8$ & $<0 \cdot 001$ & & $7 \cdot 3$ & $<0 \cdot 0001$ \\
\hline \hline
\end{tabular}

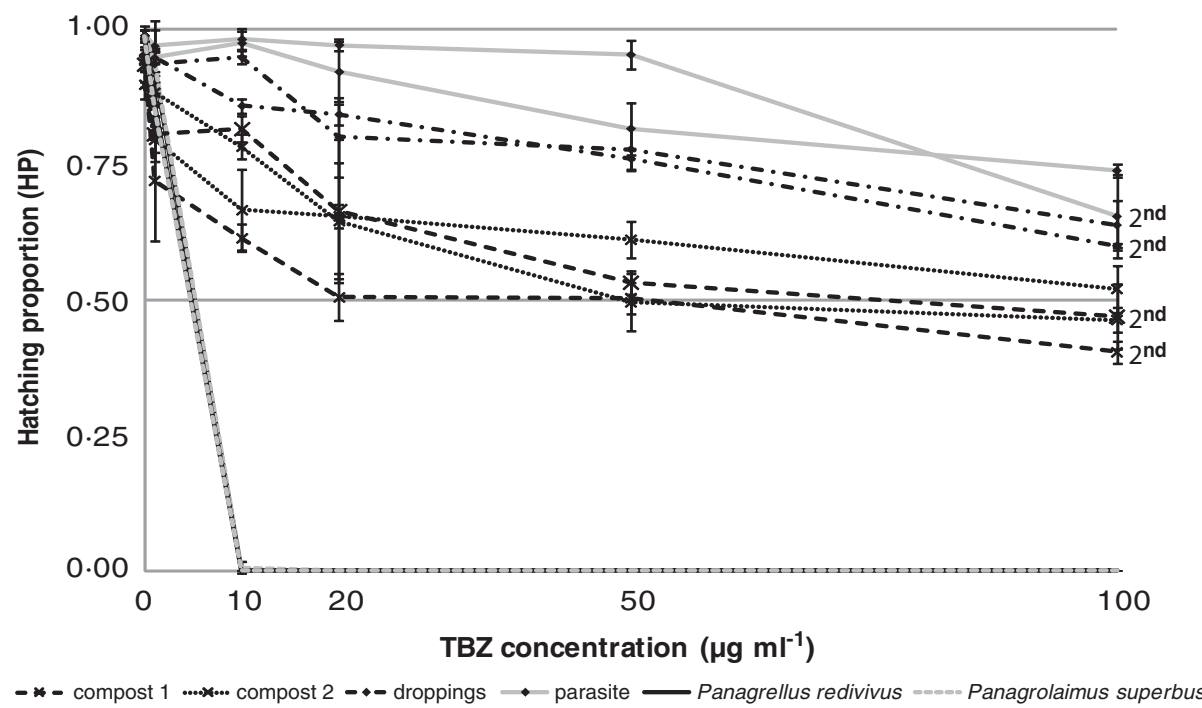

Fig. 1. The hatching proportion (HP) for all Halicephalobus $\mathrm{cf}$. gingivalis isolates ${ }^{\dagger}$ and for Panagrellus redivivus (PS1163) and Panagrolaimus superbus (DF5050) at different thiabendazole (TBZ) concentrations $\left(\mu \mathrm{g} \mathrm{ml} \mathrm{m}^{-1}\right.$ ). Data represent the mean of 3 replicates $( \pm 1$ S.D.) for 2 independent and consecutive trials. Data from the second trial are indicated $\left(2^{\text {nd }}\right) .{ }^{\dagger}$ Compost isolates, i.e. compost 1 (WB0708) and compost 2 (JB128); horse-associated isolates, i.e. parasite (SAN100) and droppings (WB0801).

lower than those of all Halicephalobus isolates (Fig. 1; Fisher's exact test: $P$ all $<0 \cdot 0001)$.

Besides an overall significant negative effect on the HPs of all the Halicephalobus isolates, significant differences were observed in their mean HP ('Isolate' effect), as well as in their response towards TBZ concentration across trials (Isolate* concentration effect) ('Table 1). Comparison of the mean HPs across trials revealed that the parasite isolate had the highest average HPs, which were significantly different from the average HPs of the droppings isolate (Tukey post-hoc, $P$ all $<0 \cdot 05$ ) and from both compost isolates at all TBZ concentrations $(P$ all $<0 \cdot 0001)$. The droppings isolate had the second highest average HPs, which were also significantly higher than the average HPs of both compost isolates at all drug concentrations $(P$ all $<0 \cdot 0001)$. Compost isolates 1 and 2 had the overall lowest average HPs of the Halicephalobus isolates, without significant $(P$ all $>0 \cdot 07$ ) mutual HP differences.

\section{Ivermectin (IVM)}

The mean HPs of the Halicephalobus isolates and of $P$. redivivus and $P$. superbus of both trials at the different IVM concentrations are shown in Fig. 2, with $0 \mu \mathrm{g} \mathrm{ml}^{-1}$ being the negative control. The average HPs of the negative controls were similar for all Halicephalobus isolates and for $P$. redivivus and $P$. superbus with an average HP ranging from 0.92 to 1 .

As for TBZ, the HPs of both $P$. redivivus and $P$. superbus soon dropped significanty lower (at $0 \cdot 1 \mu \mathrm{g} \mathrm{ml}^{-1}$ ) compared to those of the Halicephalobus isolates (Fisher's exact test: $P$ all $<0 \cdot 0001$ ). As the HPs for both $P$. redivivus and $P$. superbus even approached zero for IVM concentrations that were higher than $0 \cdot 5 \mu \mathrm{g} \mathrm{ml}^{-1}$, they were significantly lower compared to the HPs of the Halicephalobus isolates for all the remaining IVM concentrations (Fisher's exact test: $P$ all $<0 \cdot 0001)$.

Also for IVM, within the Halicephalobus isolates significant differences were observed in both the mean hatching rate and in their response to IVM concentration across both trials (Table 1). The average HPs of the parasite isolate were also the highest at all IVM concentrations, followed by those of the droppings isolate and subsequently those of compost isolate 1. Although they were not clearly separated, they were significantly different from each 


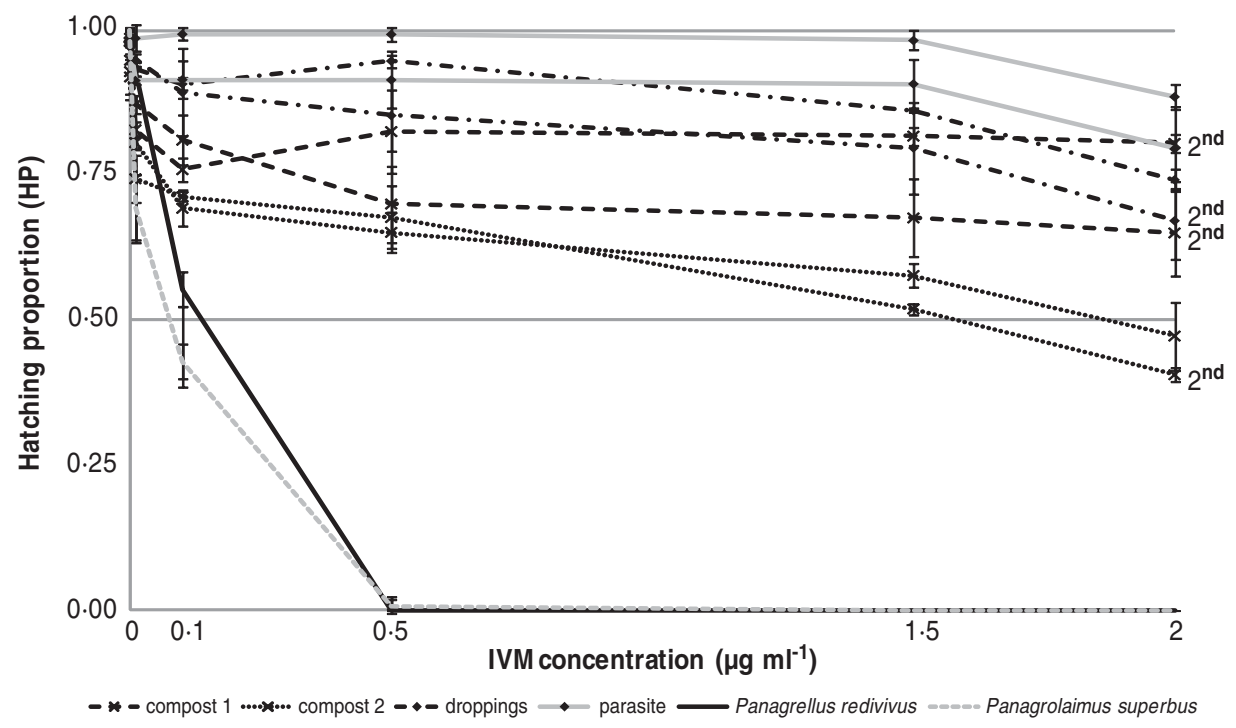

Fig. 2. The hatching proportion (HP) for all Halicephalobus cf. gingivalis isolates ${ }^{\dagger}$ and for Panagrellus redivivus (PS1163) and Panagrolaimus superbus (DF5050) at different ivermectin (IVM) concentrations $\left(\mu \mathrm{g} \mathrm{ml}^{-1}\right)$. Data represent the mean of 3 replicates $( \pm 1$ S.D.) for 2 independent and consecutive trials. Data from the second trial are indicated $\left(2^{\text {nd }}\right) .{ }^{\dagger}$ Compost isolates, i.e. compost 1 (WB0708) and compost 2 (JB128); horse-associated isolates, i.e. parasite (SAN100) and droppings (WB0801).

other $(P$ all $<0.02)$, except for the average HPs of the droppings isolate and compost isolate 1 from $1 \cdot 55 \mu \mathrm{g} \mathrm{ml}^{-1}$ onwards $(P$ all $>0 \cdot 06)$. Compost isolate 2 had the overall lowest average HPs, which were significantly lower than the average HPs of the other Halicephalobus isolates at all IVM concentrations ('Tukey post-hoc, $P$ all $<0 \cdot 0001$ ).

\section{Recovery capacity after drug treatment}

TBZ treatment showed a dose-related inhibitory effect on egg hatching for the Halicephalobus isolates and for P. redivivus and P. superbus. However, the eggs that hatched show no discernible delay in developmental rate at all TBZ concentrations, and almost all the hatched larvae developed into the adult stage. In contrast, for the tested IVM concentrations the inhibitory effect on egg hatching was less explicit. Only little influence on hatching was observed compared to the negative controls and the developmental rate of the eggs at the different IVM concentrations was the same. However, there was a dose-related effect on the survival of the juveniles and at higher IVM concentrations there was a noticeable delay in the development of the juveniles into the adult stage. At $0 \cdot 01 \mu \mathrm{g} \mathrm{ml}^{-1}$ IVM concentration the adult stage of all $H$. gingivalis isolates and $P$. redivivus and $P$. superbus was attained with a delay of 24 to $48 \mathrm{~h}$. At $0 \cdot 5-2 \mu \mathrm{g} \mathrm{ml}^{-1}$ IVM, the larvae of the Halicephalobus isolates survived, with a reduced motility, but did not develop into the adult stage. However, this negative effect on larval development was found to be reversible for the parasite isolate, the droppings isolate and compost isolate 1. Hatched larvae incubated for $76 \mathrm{~h}$ on wells containing
$1 \cdot 5 \mu \mathrm{g} \mathrm{ml}^{-1}$ IVM had a survival rate of $85 \cdot 4 \pm 4 \cdot 5 \%$ (mean \pm 1 S.D.) for the parasite isolate, $71 \cdot 6 \pm 2 \cdot 5 \%$ for the droppings isolate and $75 \cdot 8 \pm 4 \cdot 6 \%$ for compost isolate 1 . Surviving larvae were subsequently transferred onto $1 \%$ plain bacteriological agar whereupon they reached the adult stage after 3 days. The recovery rate was $94 \cdot 1 \pm 2 \cdot 3 \%$ (mean \pm 1 S.D.) for the parasite isolate, $77 \cdot 9 \pm 5.7 \%$ for the droppings isolate and $91 \cdot 1 \pm 5 \cdot 1 \%$ for the compost isolate 1 . Compost isolate 2 only had $16 \cdot 5 \pm 4 \cdot 5 \%$ surviving larvae, which did not develop into the adult stage after transfer onto plain $1 \%$ bacteriological agar. Finally, this recovery capacity could not be tested for $P$. redivivus and $P$. superbus at $1.5 \mu \mathrm{g} \mathrm{ml}^{-1}$ IVM since there were no surviving larvae at higher IVM concentrations.

\section{Influence of pre-exposure on anthelmintic tolerance}

The effect of pre-exposure with anthelmintics for approximately 12 generations was very similar for all isolates and is therefore only illustrated for compost isolate 1 (Fig. 3). For both anthelmintics, the HPs of all Halicephalobus isolates in the control treatment were significantly lower (Tukey post-hoc, $P<0 \cdot 001$ ) upon pre-exposure as opposed to the HPs of eggs deposited by nematodes which had not been preexposed, i.e. $10-20 \%$ and $37-47 \%$ lower for IVM and TBZ, respectively. The dose-response upon preexposure was nevertheless different between TBZ and IVM.

Upon pre-exposure to TBZ, the HPs exhibited limited (compost isolate 2) to no (compost isolate 1, parasite isolate, droppings isolate) concentration dependence, which was demonstrated by the lack of significant differences (Tukey post-hoc, $P$ all $>0 \cdot 05$ ) 
a.

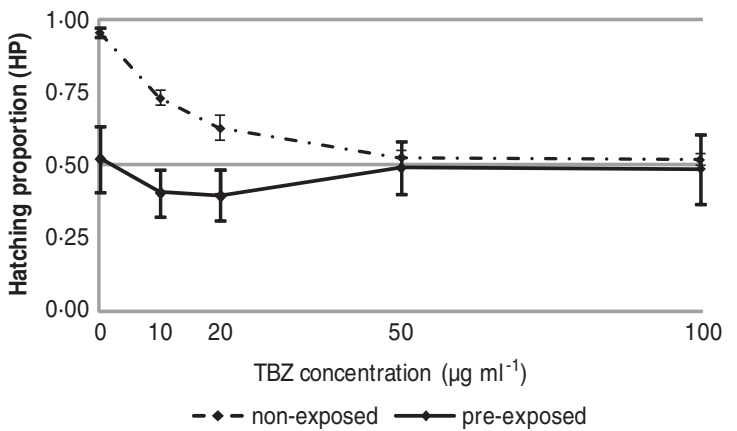

b.

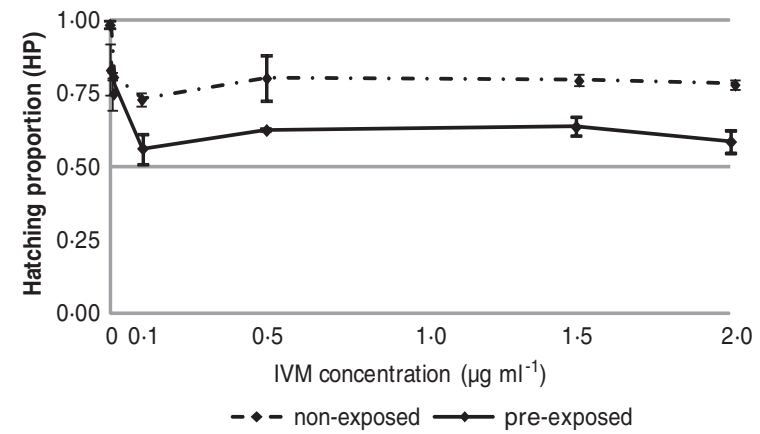

Fig. 3. The mean hatching proportion (HP) of pre-exposed eggs (dotted line) is compared with the mean HPs of non-exposed eggs (full line) for Halicephalobus compost isolate 1 (WB0708) at different TBZ (a) and IVM (b) concentrations $\left(\mu \mathrm{g} \mathrm{ml}^{-1}\right)$. Data represent the mean of 3 replicates $( \pm 1$ S.D.).

between the HPs at different drug concentrations, including the control.

Upon pre-exposure to IVM the HPs still showed a similar concentration dependence as opposed to nonpre-exposure. However, for most isolates (compost isolate 1, parasite isolate, droppings isolate) the HPs at all concentrations were significantly lower $(P$ all $<0 \cdot 05)$ than in the original experiment, except the HPs of compost isolate 2 that showed no significant difference $(P>0 \cdot 05)$ at all concentrations.

\section{DISCUSSION}

\section{Methodological considerations}

Several methodological aspects may bear upon the results of dose-effect studies like the present one. We are, however, convinced that the methods used here allow an accurate assessment of the effect of the anthelmintics used in this study. The MALDT method has been proven earlier to give reliable results concerning the detection of benzimidazole resistance (Várady et al. 2009), and by using this agar-based method the insolubility problem of IVM is eliminated (Lacey et al. 1991). Moreover, former studies have revealed that the activity of IVM incorporated in agar is higher than in aqueous solutions (Várady et al. 2009). Secondly, our negative controls of the Halicephalobus isolates, $P$. redivivus and of P. superbus have HPs close to $100 \%$. Therefore it can be assumed that the incubation conditions used here are adequate. Thirdly, the steep decrease of the HPs of $P$. redivivus and $P$. superbus compared to the relatively high HPs of the Halicephalobus isolates at higher concentrations of both TBZ and IVM confirms that effective drug treatment is detectable using this method. Finally, the highly concordant results of 2 independent experimental trials demonstrate the reproducibility of our bioassay.

\section{Tolerance versus resistance}

It is very important to distinguish between an original low, or lack of, effectiveness of an anthelmintic drug to a population and the presence of actual resistance to that same anthelmintic (Brady and Nichols, 2009). The lack of effectiveness can be seen as an existing natural tolerance to an anthelmintic even before the parasite has come in contact with the drug (Fallon et al. 1996; Coles, 2006), whereas acquired resistance is the conversion within a species of a low or absent tolerance towards a higher tolerance which is initiated by contact with the anthelmintic (James et al. 2009). The overall high hatching proportions of the Halicephalobus isolates at all concentrations tested in this study suggest the presence of some kind of natural tolerance to IVM and TBZ. This tolerance appears specific for the facultative parasitic genus Halicephalobus, since in at least some Panagrolaimidae ( $P$. redivivus and P. superbus) no tolerance was observed. The stunning tolerance of the Halicephalobus isolates to TBZ and IVM is further confirmed by the considerably higher concentrations (roughly 75 times the maximum dose used for TBZ and roughly 45 times the maximum dose used for IVM) used in the present study as compared to TBZ and IVM concentrations used in another in vitro study using the MALDT method for testing anthelmintic resistance of the obligatory parasite Haemonchus contortus (Várady et al. 2009).

Our results reveal that the horse-associated Halicephalobus isolates are highly tolerant for both tested anthelmintic drugs and that the Halicephalobus compost isolates show an anthelmintic tolerance that is generally lower. Thus, our results also reveal a remarkable trend of increasing tolerance from fully free-living isolates towards horse-associated isolates, which is especially true for TBZ. This difference in tolerance to anthelmintics between the Halicephalobus isolates may be associated with earlier contact to these anti-parasitic drugs. However, none of the Halicephalobus strains have been found to be fully susceptible to either anthelmintic. Since there is no fully susceptible strain available, no actual acquired resistance can be proven (Brady and Nichols, 2009). In addition, the pre-exposure experiments did not show a decreased susceptibility to the 
tested anthelmintics. The average HPs of all preexposed isolates in the control treatment (no anthelmintic added) were considerably lower (by $10-47 \%$ ) than those of non-pre-exposed nematodes, which indicates that the fitness of all isolates is negatively affected by prolonged exposure to the anthelmintics, resulting in a lower egg viability. This type of negative effect of a chemical compound on nematode egg viability has been shown earlier for e.g. tannins on gastro-intestinal parasites (Min and Hart, 2003). Further, the HPs under anthelmintic exposure exhibited only limited (compost isolate 2) to no (the other isolates) concentration dependence for TBZ and similar (compost isolate 2) or generally lower HPs (the other isolates) for IVM. This is contrary to the idea that the high tolerances observed in short exposure experiments and the differences between the horse-associated and the other isolates would be due to a true resistance. Moreover, differences in the D2D3 expansion segment of the LSU rDNA region (data not shown) shows a remarkable interpopulation variation. However, phylogenetic analyses, including GenBank (Benson et al. 2008) sequences, appointed our Halicephalobus isolates (WB0801, GenBank HQ697251 and WB0708, GenBank JF706244) within an internally unresolved $H$. gingivalis clade (data not shown). Light microscopically, they are not discernible from other $H$. gingivalis isolates (JB128 and SAN100) and should therefore be referred to as Halicephalobus cf. gingivalis. Most likely, biological differences including anthelmintic tolerance between the Halicephalobus isolates are associated with different evolutionary lineages or cryptic species as indicated by these D2D3 sequence differences.

Finally, since even the very high anthelmintic concentrations used in the present study appear ineffective to control the Halicephalobus isolates and since IVM administered to horses at the recommended dosage has a maximum plasma persistence of 4 to $62 \mathrm{ng} \mathrm{ml}^{-1}$ (Gokbulut et al. 2010), it is very unlikely that in vivo anthelmintic treatments are effective for infections with this facultative parasite. This is supported by the medical history of horses that suffered lethal infections of this nematode species in spite of regular treatment with common anthelmintics (e.g. Boswinkel et al. 2006, Ferguson et al. 2008).

\section{Halicephalobus as a model organism}

In research on the effects of anti-parasitic drugs, the use of free-living nematodes for in vitro experiments has the advantage of allowing observations on their complete life cycle, including survival and (delayed) development. In contrast, obligatory animal parasites can only be followed until the infective stage. Caenorhabditis elegans has been used as a model for studies on the development of anthelmintic resistance and the testing of the efficiency of new drugs (e.g. Simpkin and Coles, 1980; Sangster et al. 2002; James and Davey, 2009). Since its complete genome is known, C. elegans is especially suitable for studying the effects of anthelmintics at the gene level (HoldenDye and Walker, 2007). However, the usefulness of C. elegans as a model for parasitic nematodes has been questioned (Geary and Thompson, 2001), among other reasons simply because it is not capable of parasitism in its natural environment. Halicephalobus gingivalis shares several of the advantages of C. elegans as a model organism: it is amenable to culture under laboratory conditions; it has a very short generation time $\left(2\right.$ days at $\left.30^{\circ} \mathrm{C}\right)$, produces a lot of offspring, can be cultured in liquid (monoxenic as well as axenic) as well as on solid media (Fonderie et al. 2009) and at temperatures ranging from $4^{\circ} \mathrm{C}$ to more than $40^{\circ} \mathrm{C}$ (personal observations, unpublished). Additionally, $H$. gingivalis is capable of parasitism in its natural environment. Moreover, since complete genome sequencing is nowadays relatively fast and easy (Elsworth et al. 2011), the 'genetic barrier' can easily be overcome. Although the lack of a susceptible isolate is a drawback to the use of Halicephalobus cf. gingivalis as a model organism for testing new anthelmintics, the presence and ease of cultivation of susceptible close relatives such as Panagrellus and Panagrolaimus provides great potential as an experimental tool for testing the effects of various drugs on a model system encompassing a range of tolerances and including an organism with a life-history intermediate between that of obligatory parasites and of fully free-living nematodes.

\section{ACKNOWLEDGEMENTS}

We kindly thank J. Baldwin and S. Nadler for providing the JB128 and SAN100 H. gingivalis isolates, respectively. We further thank A. Vierstraete for sequencing and E. Dens for practical support in the realization of the experiments.

\section{FINANCIAL SUPPORT}

This research was supported by funding from the Foundation of Scientific Research, Flanders (FWO, grant number G003306N).

\section{REFERENCES}

Agresti, A. (2002). Categorical Data Analysis 2nd Edn. Wiley-Interscience, New Jersey, USA.

Akagami, M., Shibahara, T., Yoshiga, T., Tanak, N., Yaguchi, Y., Onuki, T., Kondo, T., Yamanaka, T., and Kubo, M. (2007). Granulomatous nephritis and meningoencephalomyelitis caused by Halicephalobus gingivalis in a pony gelding. Fournal of Veterinary Medical Science 69, 1187-1190.

Anderson, R. C., Linder, K. E. and Peregrine, A.S. (1998). Halicephalobus gingivalis (Stefansky, 1954) from a fatal infection in a horse in Ontario, Canada with comments on the validity of $H$. gingivalis and a review of the genus. Parasite 5, 255-261.

Andrássy, I. (1984). Klasse Nematoda (Ordnungen Monhysterida, Desmoscolecida, Araeolaimidae, Chromadorida, Rhabditida). Gustav Fischer Verlag, Stuttgart, Germany. 
Benson, D. A., Karsch-Mizrachi, I., Lipman, D. J., Ostell, J. and Wheeler, D. (2008). GenBank. Nucleic Acids Research 36, D25-D30. doi: 10.1093/nar/gkm929

Blunden, A. S., Khalil, L. F. and Webbon, P. M. (1987). Halicephalobus deletrix infection in a horse. Equine Veterinary fournal 19, 255-260.

Boswinkel, M., Neyens, I. J.S. and Sloet van OldruitenborghOosterbaan, M. M. (2006). Halicephalobus gingivalis infection in a 5-year old Tinker gelding. Tijdschrift voor Diergeneeskunde 131, 74-80.

Brady, H. A. and Nichols, W. T. (2009). Drug resistance in equine parasites: an emerging global problem. Fournal of Equine Veterinary Science 29, 285-295.

Brenner, S. (1974). The genetics of Caenorhabditis elegans. Genetics 77, 71-94.

Coles, G. C. (2006). Drug resistance or drug tolerance in parasites. Trends in Parasitology 22, 348.

Coles, G. C., Jackson, F., Pomroy, W. E., Prichard, R. K., von SamsonHimmelstjerna, G., Silvestre, A., Taylor, M. A. and Vercruysse, J. (2006). The detection of anthelmintic resistance in nematodes of veterinary importance. Veterinary Parasitology 136, 167-185.

Dunn, D. G., Gardiner, C. H., Dralle, K. R. and Thilsted, J. P. (1993). Nodular granulomatous posthitis caused by Halicephalobus (syn. Micronema) sp. in a horse. Veterinary Pathology 30, 586-589.

Elsworth, B., Wasmuth, J. and Blaxter, M. (2011). NEMBASE4: The nematode transcriptome resource. International Fournal for Parasitology $\mathbf{4 1}$ 881-894.

Fallon, P. G., Tao, L.F., Ismail, M. M. and Bennett, J. L. (1996). Schistosome resistance to praziquantel: Fact or artifact? Parasitology Today 12, 316-320.

Ferguson, R., van Dreumel, T., Keystone, J.S., Manning, A. Malatestinic, A., Caswell, J. L. and Peregrine, A.S. (2008) Unsuccessful treatment of a horse with mandibular graulomatous osteomyelitis due to Halicephalobus gingivalis. Canadian Veterinary Fournal 49 1099-1103.

Fonderie, P., Willems, M., Bert, W., Houthoofd, W., Steel, H., Claeys, M. and Borgonie, G. (2009). Intestine ultrastructure of the facultative parasite Halicephalobus gingivalis (Nematoda: Panagrolaimidae) Nematology 11, 859-868.

Geary, T. G. and Thompson, D. P. (2001). Caenorhabditis elegans: How good a model for veterinary parasites? Veterinary Parasitology 101, 371-386. Geraert, E., Sudhaus, W., Lenaerts, L. and Bosmans, E. (1988) Halicephalobus laticauda sp. n., a nematode found in a Belgian coal mine (Nematoda, Rhabditida). Annales de la Société Royale Zoologique de Belgique 118, 5-12.

Gokbulut, C., Cirak, V.Y., Senlik, B., Aksit, D., Durmaz, M. and McKellar, Q. A. (2010). Comparative plasma disposition, bioavailability and efficacy of ivermectin following oral and pour-on administrations in horses. Veterinary Parasitology 170, 120-126.

Holden-Dye, L. and Walker, R. J. (2007).Anthelmintic drugs In WormBook (ed. The C. elegans Research Community, WormBook) doi/ 10.1895/wormbook.1.7.1, http://www.wormbook.org.

Isaza, R., Schiller, C. A., Stover, J., Smith, P. J. and Greiner, E. C. (2000). Halicephalobus gingivalis (Nematoda) infection in a Grevy's zebra (Equis grevyi). Fournal of Zoo and Wildlife Medicine 31, 77-81.

James, C. E. and Davey, M. W. (2009). Increased expression of ABC transport proteins is associated with ivermectin resistance in the model nematode Caenorhabditis elegans. International fournal for Parasitology 39 , 213-220.

James, C. E., Hudson, A. L. and Davey, M. W. (2009). Drug resistance mechanisms in helminths: is it survival of the fittest? Trends in Parasitology $25,328-335$.
Johnson, J. S., Hibler, C. P., Tillotson, K. M. and Mason, G. L. (2001). Radiculomeningomyelitis due to Halicephalobus gingivalis in a horse. Veterinary Pathology 38, 559-561.

Kenward, M. G. and Roger, J. H. (1997). Small sample inference for fixed effects from restricted maximum likelihood. Biometrics 53, 983-997.

Lacey, E., Redwin, J.M., Gill, G.H., Demargheriti, V. M. and Waller, P. J. (1991). A larval development assay for the simultaneous detection of broad spectrum anthelmintic resistance. In Resistance of Parasites to Anti-parasitic Drugs (ed. Boray, J. C., Martin, P. J. and Roush, R. T.), pp. 177-184. MSD AGVET, Rahway, New Jersey, USA.

Min, B. R. and Hart, S. P. (2003). Tannins for suppression of internal parasites. Fournal of Animal Science 81, E102-E109.

Müller, S., Grzybowski, M., Sager, H., Bornand, V. and Brehm, W. (2008). A nodular granulomatous posthitis caused by Halicephalobus sp. in a horse. Veterinary Dermatology 19, 44-48.

Nadler, S. A., Carreno, R. A., Adams, B. J., Kinde, H., Baldwin, J. G. and Mundo-Ocampo, M. (2003). Molecular genetics and diagnosis of soil and clinical isolates of Halicephalobus gingivalis (Nematoda: Cephalobina: Panagrolaimoidea), an opportunistic pathogen of horses. International Fournal for Parasitology 33, 1115-1125.

Ondrejka, S. L., Procop, G. W., Lai, K. K. and Prayson, R. A. (2010) Fatal parasitic meningoencephalomyelitis caused by Halicephalobus deletrix. A case report and review of the literature. Archives of Pathology and Laboratory Medicine 134, 625-629.

Patel, M. R. (1997). Effects of ivermectin on eggs and first-stage larvae of nematodes. Bios 68, 152-162.

Pearce, S. G., Bouré, L. P., Taylor, J. A. and Peregrine, A. S. (2001) Treatment of a granuloma caused by Halicephalobus gingivalis in a horse. Fournal of the American Veterinary Medical Association 219, 1735-1738.

Rames, D. S., Miller, D. K., Barthel, R., Craig, T. M., Dziezyc, J., Helman, R. G. and Mealey, R. (1995). Ocular Halicephalobus (syn. Micronema) deletrix in a horse. Veterinary Pathology 32, 540-542.

Sangster, N.C., Batterham, P., Chapman, H. D., Duraisingh, M., Le Jambre, L., Shirley, M., Upcroft, J. and Upcroft, P. (2002) Resistance to antiparasitic drugs: the role of molecular diagnosis. International fournal for Parasitology 32, 637-653.

Shokoohi, E., Abolafia, J. and Zad, J. (2007). Nematodes of the order Rhabditida from Tehran province, Iran. The family Panagrolaimidae with description of Halicephalobus persicus sp. n. and a key to species of Halicephalobus Timm, 1956. Nematology 9, 693-711.

Simpkin, K. G. and Coles, G. C. (1980). The use of Caenorhabditis elegan for anthelmintic screening. Fournal of Chemical Technology and BioTechnology 31, 66-69.

Spalding, M. G., Greiner, E. C. and Green, S. L. (1990). Halicephalobus (Micronema) deletrix infection in two half-sibling foals. Fournal of the American Veterinary Medical Association 196, 1127-1129.

Steel, H., de la Peña, E., Fonderie, P., Willekens, K., Borgonie, G. and Bert, W. (2010). Nematode succession during composting and the potential of the nematode community as an indicator of compost maturity. Pedobiologia 53, 181-190.

Stefansky, W. (1954). Rhabditis gingivalis sp. n. parasite trouvé dans un granulome de la gencive chez un cheval. Acta Parasitologica 1, 329-334.

Taylor, M. A., Hunt, K. R. and Goodyear, K. L. (2002). Anthelmintic resistance detection methods. Veterinary Parasitology 103, 183-194.

Ura, K., Kai, T., Sakata, S., Iguchi, T. and Arizono, K. (2002). Aquatic acute toxicity testing using the nematode Caenorhabditis elegans. Fournal of Health Science 48, 583-586.

Várady, M., Čorba, J., Letková, V. and Kováč, G. (2009). Comparison of two versions of larval development test to detect anthelmintic resistance in Haemonchus contortus. Veterinary Parasitology 160, 267-271. 